\title{
La ineficacia de la regulación legal de despido y su necesaria reconsideración a la luz de la normativa internacional
}

\author{
The inefficiency of the legal regulation of dismissal and its \\ necessary reconsideration in the light of international regulations
}

\author{
Beatriz Rodríguez Sanz de Galdeano* \\ Profesora Titular de Derecho del Trabajo y de la Seguridad Social \\ Universidad Pública de Navarra
}

Recibido: 4/10/2021

Aceptado: 16/10/2021

doi: https://doi.org/10.20318/labos.2021.6487

Eesumen: $\quad$ En el presente artículo se lleva a cabo una revisión del régimen legal de despido
con el doble objetivo de garantizar su eficacia y su respeto a las normas inter-
nacionales ratificadas por Espańa. La realidad práctica demuestra la prolifera-
ción, por diferentes motivos, del despido sin causa y el recurso mayoritario a
la contratación temporal como cauce de flexibilidad. Por otro lado, el sistema
legal de indemnización tasada halla difícil acomodo en la versión revisada de la
Carta Social Europea, recientemente ratificada por nuestro país. Partiendo de
estas premisas, se propone una reconsideración del procedimiento de despido
con el objetivo de detectar las conductas empresariales arbitrarias y dar una
mayor certidumbre en cuanto a la concurrencia de la causa y, en consecuencia,
la procedencia del despido.
Palabras clave:
Despido, indemnización por despido, dualidad del mercado de trabajo, refor-
ma laboral.
This paper examines Spanish dismissal regulation with the aim of guaranteeing
its effectiveness and its respect for international regulation ratified by Spain.
The reality shows the increase in, for different reasons, termination of contract
without cause and the use of temporary contracts as a way of flexibility. On the
other hand, Spanish regulation about compensation in case of termination of
employment shall no respect the revised version of the European Social Char-
ter, recently ratified by our country. On the basis of the above arguments, a re-
consideration of the dismissal regulation is proposed in order to detect arbitrary
actions and provide greater certainty.
Dismissal, compensation for dismissal, dualism in the labor market, labor reform. 


\section{Introducción: dualidad del mercado de trabajo y régimen legal de despido. Nuevos elemen- tos para un debate}

Cada cierto tiempo sacude el debate de actualidad de este país y también el debate de la doctrina laboralista y de los economistas, la temporalidad como característica estructural y patológica de nuestro mercado de trabajo. Al hilo de este debate, se vuelven a plantear proposiciones de reforma normativa con el objeto de reducir esa temporalidad y facilitar la reactivación del empleo. Una de las proposiciones más recurrentes en los últimos tiempos es la introducción del conocido como contrato único. Asimismo, suele ser habitual el planteamiento de la necesidad de reducción de la indemnización por despido. Estas posiciones parten de la premisa de que abaratar los costes de extinción serviría para animar la contratación laboral indefinida, ya que el empresario dispondría de un margen más cierto y económicamente más barato, para prescindir xqxade mano de obra en el caso de que lo necesitara y no recurriría a la contratación temporal como instrumento de flexibilidad y adaptación fundamental en caso de crisis.

Desde otro punto de vista, suele ser habitual advertir del difícil encaje en nuestro marco normativo constitucional y legal del modelo de contrato único. Asimismo, se suele apuntar la ineficacia de la reducción de la indemnización por despido para estimular la contratación y evitar la temporalidad y la necesidad de explorar otras vías ${ }^{1}$.

En el marco de este debate han irrumpido en los últimos meses nuevos elementos que permiten un replanteamiento de alguna de las cuestiones. Así, por un lado, ha tenido lugar una crisis sanitaria sin precedentes que ha obligado a la puesta en marcha de medidas de contención del despido y de apoyo a los empresarios que optaban por la suspensión de contratos o la reducción de empleo temporal. Por otro lado, estas medidas han venido acompañadas de una prohibición de despido que ha reabierto el tradicional debate en torno a las consecuencias del despido ilegítimo. Junto a ello, ha tenido lugar la aprobación de la versión revisada Carta Social Europea por parte de nuestro país, lo cual, obliga a una interpretación de nuestra normativa interna acorde con sus prescripciones en materia de despido y, muy en particular, obliga a tener en cuenta los recientes pronunciamientos del Comité Europeo de Derechos Sociales (ECSR) sobre esta cuestión.

Partiendo de este estado doctrinal brevemente descrito, el objeto de este trabajo es realizar una reflexión sosegada sobre la regulación del despido. No se pretende volver a plantear la viabilidad del recurso al contrato único o la oportunidad de la reducción de la indemnización por despido, sino que se pretende llamar la atención sobre una característica de nuestro modelo normativo de despido, en el que la mayoría de la doctrina laboralista y también los economistas y prácticos del derecho coinciden: su ineficacia.

En efecto, en medio del debate en torno a la situación del mercado de trabajo español existe un cierto consenso sobre la ineficacia del actual modelo normativo de despido. Con palabras del profesor Desdentado Bonete: “... El régimen jurídico del despido en España es un ejemplo clamoroso de ineficacia de las normas o, lo que es más grave, de una ineficacia de las normas programada por el propio Derecho que parece sometido a un trastorno bipolar: máxima protección para unos trabajadores y protección mínima o nula para otros" ${ }^{2}$. En la misma línea el profesor Goerlich Peset

\footnotetext{
${ }^{1}$ RODRÍGUEZ-PIÑERO y BRAVO-FERRER, M., “Sobre el contrato único“, Relaciones Laborales, núm. 1, 2009, pp. 111 y ss. GORELLI HERNÁNDEZ, J., "La reducción de los costes de la extinción del contrato por despido disciplinario: ¿necesidad jurídica?”, Revista de Derecho Social, núm. 50, 2010, pp. 41 y ss. LAHERA FORTEZA, J., “¿Es jurídicamente viable el contrato único?”, La Ley, núm. 8177, 2013; CONDE RUIZ, J.I. y LAHERA FORTEZA, J., "Contra la dualidad laboral”, Economistas, núm. 174, 2021, pp. 102 y ss. Ampliamente, con un enfoque jurídico-económico: GIMENO DÍAZ DE ATAURI, P., El coste del despido y otras formas de terminación del contrato por iniciativa empresarial: un análisis jurídico y económico, Lex Nova, 2014.

${ }^{2}$ DESDENTADO BONETE, A., "Introducción a un debate. Los despidos económicos en España”, en AA.VV. (dir.: DESDENTADO BONETE, A, coord.: DE LA PUEBLA PINILLA, A.): Despido y crisis económica. Los despidos económicos tras la reforma laboral. Un análisis desde el Derecho y la Economía, Lex Nova, Valladolid, p. 31.
} 
Beatriz Rodríguez Sanz de Galdeano La ineficacia de la regulación legal de despido y su necesaria reconsideración...

apuntaba: "creo que la razón fundamental de la existencia de la indicada 'brecha' se encuentra en el insatisfactorio funcionamiento del despido por razones económicas que ha caracterizado nuestro sistema jurídico"3.

Ciertamente, el modelo normativo de despido en nuestro país resulta un paradigma de ineficacia normativa, por los motivos que se verán a continuación, y que han provocado un recurso excesivo a la contratación temporal y la proliferación del despido sin causa y/o del reconocimiento anticipado de la improcedencia. Resulta, por ello, necesario un replanteamiento de algunas de sus premisas básicas con el objetivo de, por un lado, garantizar una certidumbre al empresario en cuanto a las causas que justifican la extinción temporal y, por otro, ofrecer al trabajador una vía de reparación suficiente.

\section{Algunos efectos patológicos de la regulación del despido}

\subsection{La preferencia por la conciliación extrajudicial en materia de despido y la huida del empresario al despido sin causa y su reconocimiento}

Las estadísticas en materia de mediación, arbitraje y conciliación laboral elaboradas por el Consejo General del Poder Judicial, ponen de manifiesto cómo más del 50 \% de los asuntos relativos a despidos terminan con avenencia ${ }^{4}$.

Así, en el año 2019 de un total de 253.636 asuntos, 135.437 se conciliaron en vía extrajudicial, mientas que 63.162 terminaros sin avenencia y el resto terminaron por otros motivos, como el desistimiento.

En el año 2020, estos datos se mantienen en términos similares y, de un total de 178.961 asuntos en materia de despidos, 96.810 terminaron con avenencia, 38.225 sin avenencia y el resto por otros motivos.

En cuanto al coste del despido en el año 2019, la cantidad media que se acordó fue de 18.592,9 euros. En el año 2020, la cuantía media de las cantidades acordadas en conciliación ascendió a $22.705,9$ euros.

Si se analizan los datos estadísticos de asuntos resueltos judicialmente en materia de despido 5 , esto es, los datos de asuntos que no fueron conciliados en vía extrajudicial y acaban siendo resueltos en el juzgado, resulta que en el ańo 2019 hubo un total de 108.698 asuntos, de los cuales 21.599 terminaron con sentencia favorable al trabajador, 4445 con sentencia favorable en parte y 6.550 con sentencia desfavorable, Además 50.307 se conciliaron en vía judicial

En el año 2020 estos datos se mantienen en parecidos términos y hubo un total de 107.834 despidos, de los cuales 20.814 terminaron con sentencia favorable al trabajador, 4.078 con sentencia favorable en parte al trabajador y 5.563 con sentencia desfavorable. En este año 2020 un total de 49.005 asuntos fueron conciliados en vía judicial.

En cuanto a la indemnización media por despido, a partir del último estudio elaborado por el Ministerio sobre el despido y su coste entre los años 2015 a 2018, cabe concluir que la indem-

\footnotetext{
${ }^{3}$ GOERLICH PESET, J.M., “¿Contrato único o reforma del despido por causas empresariales?”, Relaciones Laborales, 2010-I, p. 1206

${ }^{4}$ Disponible en: https://www.poderjudicial.es/cgpj/es/Temas/Estadistica-Judicial/Estadistica-por-temas/Medios-alternativos-deresolucion-de-conflictos/Mediacion--Arbitraje-y-Conciliacion-laborales/

${ }^{5}$ Estadística de asuntos judiciales sociales, elaborada por el CGPJ, disponible en https:/www.poderjudicial.es/cgpj/es/Temas/ Estadistica-Judicial/Estadistica-por-temas/Datos-penales--civiles-y-laborales/Civil-y-laboral/Asuntos-Judiciales-Sociales/.
} 
nización media por despido se situó en el año 2015 en los 10.044 euros, en el año 2016 en 10.090 euros, en el año 2019 en 9.129 euros y en el año 2018 en 9.306 euros.

Según los datos del año 2020, las cantidades totales abonadas por sentencia tanto favorable, como favorable en parte al trabajador en materia de despido ascendieron a 282.056.325, 1 y afectaron a un total de 33.248 trabajadores; de lo cual cabe concluir que la cantidad media por despido recibida por cada trabajador (incluyendo los trabajadores con sentencias favorables en parte) ascendió a 8.483,40 euros.

Estos datos demuestran como aproximadamente la mitad de los despidos se concilian en vía extrajudicial. Del resto de asuntos que llegan al juzgado aproximadamente la mitad se concilian en vía judicial. En los casos en los que no se logra la conciliación ni extrajudicial, ni vía judicial, la sentencia es favorable al trabajador en la mayor parte de las ocasiones. Asimismo, de los datos brevemente referenciados, se observa como el coste de la indemnización por despido es mayor en los procedimientos que concluyen mediante conciliación extrajudicial, que en los procedimientos que se resuelven en sentencia. La razón de ello puede encontrarse en que el empresario, bien por la certeza en cuanto a la improcedencia del despido, bien por no esperar a una incierta resolución judicial prefieren acordar la indemnización en vía extrajudicial y evitar así el proceso. Ello, a pesar de que, con la eliminación del despido exprés en la última reforma, el empresario no tiene tanto incentivo para pactar en la conciliación extrajudicial, ya que el coste del despido no se incrementa (salvo que se pida la readmisión y entonces corran salarios de tramitación). Por lo tanto, cabe intuir que en la mayor parte de las ocasiones la conciliación en vía extrajudicial obedecerá a la conciencia por parte del empresario de la ilegalidad del despido.

Los datos estadísticos no permiten un conocimiento cualitativo detallado de los motivos que originan el despido, ahora bien, la experiencia práctica pone de manifiesto que cuando el empresario decide el despido de un trabajador y pretende reconocer su improcedencia, alega una causa irreal o no suficientemente sólida, en la carta de despido y posteriormente reconoce su improcedencia. Así, suele ser habitual que se aluda como causa del despido a la disminución del rendimiento del trabajador, o que, sin más, se aleguen causas ETOP, sin una justificación suficientemente fundada. Resulta, por tanto, que como señalaba el profesor Gorelli Hernández: "los costes reales del despido son más altos que los costes legales". La cuestión que se plantea es por qué el empresario prefiere asumir el mayor coste de la indemnización por despido en esa vía extrajudicial que afrontar la tarea de justificar el despido. Ello puede deberse, como se ha señalado, a que efectivamente el despido no tiene causa alguna, el empresario ha decidido prescindir de un trabajador sin motivo alguno. Ahora bien, en otros casos puede ocurrir que exista un motivo para el despido encuadrable en alguna de las causas que lo justifican pero que las dificultades de prueba en el proceso y la incertidumbre sobre la decisión judicial avoquen al empresario al despido sin causa. En este punto, parece que juegan un papel importante los costes procesales de la tramitación judicial y, muy en particular en los despidos económicos, los costes derivados de la prueba pericial ${ }^{7}$, de resultado no siempre cierto.

Esto nos lleva a una de las segundas características de nuestro modelo legal del despido, la incertidumbre en cuanto a la causa y al tipo de despido.

${ }^{6}$ GORELLI HERNÁNDEZ, J., El coste económico del despido o el precio de la arbitrariedad, Consejo Andaluz de Relaciones Laborales, 2010, pp. 264 y 265.

7 HERNÁNDEZ VITORIA, M.J., "La prueba en los despidos por crisis y mejora de la empresa y su control judicial. Una perspectiva jurídica", en AA.VV. (dir.: DESDENTADO BONETE, A, coord.: DE LA PUEBLA PINILLA, A.): Despido y crisis económica. Los despidos económicos tras la reforma laboral. Un análisis desde el Derecho y la Economía, Lex Nova, Valladolid, pp. 147 y ss. 
Beatriz Rodríguez Sanz de Galdeano La ineficacia de la regulación legal de despido y su necesaria reconsideración...

\subsection{Incertidumbre en torno a la procedencia del despido: la problemática definición de las causas y el dudoso ámbito del despido colectivo}

De acuerdo con nuestro marco legal, la extinción unilateral del trabajador por voluntad del empresario puede tener su origen en causas objetivas ajenas a la empresa, tales como la ineptitud sobrevenida o la falta de adaptación del trabajador a las modificaciones técnicas [(art. 52 a) y b)]. Puede deberse a causas objetivas vinculadas a la empresa, como son las causas ETOP, definidas en el art. 51.1 TRET. Puede, por último, tener su origen en un incumplimiento culpable del trabajador, que dará lugar a un despido disciplinario (art. 54 TRET). Para que el despido sea procedente el empresario debe probar la causa y seguir el procedimiento legal correspondiente.

Por otro lado, cuando el despido tenga su origen en causas empresariales y afecte a un umbral mínimo de trabajadores, se considerará despido colectivo y habrá de tramitarse siguiendo el procedimiento específico que, como es sabido, incluye un trámite de consultas (art. 51 TRET).

Uno de los aspectos de nuestra regulación que generalmente suscitan controversia y que en ocasiones está en el origen del reconocimiento anticipado de la improcedencia es la incertidumbre en cuanto a la concurrencia de la causa ${ }^{8}$.

Cuando se trata de causas ETOP el empresario debe acreditar según la dicción del Estatuto de los Trabajadores, bien la existencia de una situación económica negativa, bien la concurrencia de cambios en los medios o instrumentos de producción, bien la existencia de cambios en los sistemas y métodos de trabajo del personal o en el modo de organizar la producción o bien cambios en la demanda de productos o servicios.

Las reformas de los últimos años han tratado de concretar las causas ETOP definidas en el art. 52 TRET 9 . En la reforma del año 2010, el legislador trató de concretar la causa ETOP con el fin confesado de corregir deficiencias en la regulación y evitar el recurso al despido disciplinario improcedente en casos en los que concurren causas ETOP. Señalaba literalmente la exposición de motivos de la Ley 35/2010, de 17 de septiembre: "La experiencia obtenida en los últimos años ha puesto de manifiesto, particularmente en los dos últimos años, algunas deficiencias en el funcionamiento de las vías de extinción previstas en los artículos 51 y 52 c) del texto refundido de la Ley del Estatuto de los Trabajadores, aprobado por el Real Decreto Legislativo 1/1995, de 24 de marzo, al desplazar muchas extinciones de contratos indefinidos realmente basadas en motivaciones económicas o productivas hacia la vía del despido disciplinario improcedente.

Se ha estimado necesaria, en consecuencia, una nueva redacción de estas causas de extinción que proporcione una mayor certeza tanto a trabajadores y a empresarios como a los órganos jurisdiccionales en su tarea de control judicial."

Se observa que con esta reforma se trataba de perfilar mejor el concepto de causas ETOP y se incidió igualmente en la razonabilidad de la medida, si bien, según la redacción literal no siempre era necesaria una situación negativa de la empresa, sino que también era posible recurrir a las extinciones para garantizar la competitividad de la empresa o mejorar su situación en el mercado.

El cambio más importante tuvo lugar con la reforma laboral del año 2012, llevada a cabo mediante la Ley 3/2012, de 6 de julio, que volvió a incidir en la definición de la causa y, lo que fue más novedoso, pareció prescindir de la necesaria conexión funcional con una situación negativa o garantía de la viabilidad de la empresa. La propia exposición de motivos de la ley señalaba: "Por su parte, los despidos objetivos por las mismas causas han venido caracterizándose por una ambivalen-

\footnotetext{
${ }^{8}$ GOERLICH PESET, J.M., “¿Contrato único o reforma del despido por causas empresariales?”, op. cit., pp. 1221 y ss.

9 MANEIRO VÁZQUEZ, Y., "Despido en tiempos de crisis. Balance de las modificaciones españolas en los últimos tiempos", Dereito vol. 22, núm. 2, 2013.
} 
te doctrina judicial y jurisprudencia, en la que ha primado muchas veces una concepción meramente defensiva de estos despidos, como mecanismo para hacer frente a graves problemas económicos, soslayando otras funciones que está destinado a cumplir este despido como cauce para ajustar el volumen de empleo a los cambios técnico-organizativos operados en las empresas. Ello explica que las empresas se decantaran, a menudo, por el reconocimiento de la improcedencia del despido, evitando un proceso judicial sobre el que no se tenía demasiada confianza en cuanto a las posibilidades de conseguir la procedencia del despido, debiendo, por tanto, abonar la indemnización por despido improcedente más el coste adicional que suponían los salarios de tramitación”. Se observa cómo en el espíritu de la reforma se encontraba la necesidad de dar con una definición de causa objetiva que permitiera eliminar la incertidumbre de una interpretación judicial.

Sin embargo, el Tribunal Supremo, en una jurisprudencia ya consolidada ${ }^{10}$ concluyó que, aunque el preámbulo de la reforma del año 2012 señala que el control de los despidos debe ceñirse a la concurrencia de las causas y no debe entrar en juicios de oportunidad, ello no obsta a que se pueda llevar a cabo un control judicial sobre la razonabilidad de la medida empresarial. Esta razonabilidad exige un análisis de la existencia de la causa tipificada legalmente como justificativa de la medida empresarial, sobre la adecuación de la medida para hacer frente a las circunstancias económicas y organizativas acreditadas y sobre la racionalidad de la medida entendiendo que no son conforme a derecho las medidas empresariales que supongan una desproporción entre el objetivo fijado y las medidas extintivas ${ }^{11}$.

Por lo tanto, según la jurisprudencia del Tribunal Supremo sigue siendo necesaria la acreditación de la causa y su conexión funcional con la decisión concreta de despido. Esto determina que el empresario que desea recurrir al despido por causas ETOP debe realizar un doble esfuerzo probatorio, por un lado, debe acreditar la causa, y, por otro lado, debe justificar la necesidad de amortización del puesto y su proporcionalidad. Esta exigencia sigue dejando un cierto margen lógico de incertidumbre, que todavía puede llevar a que el empresario, ante la incertidumbre en cuanto al apreciación judicial sobre la proporcionalidad del despido, decida reconocer de forma anticipada la improcedencia y evitar así el proceso.

También en el ámbito de los despidos disciplinarios existe un margen de incertidumbre en cuanto a la concurrencia de la causa, por cuanto, el empresario ha de acreditar no sólo el incumplimiento del trabajador, sino también su carácter grave y culpable. Ciertamente el art. 54.2 contiene un elenco de incumplimientos contractuales del trabajador, algunos de los cuales no ofrecen margen de duda en cuanto a su gravedad, pero en todo caso, el empresario ha de probar su concurrencia y, en algunos casos, existe un margen de valoración e interpretación en cuanto a la concurrencia de la gravedad y culpabilidad del incumplimiento por parte del trabajador. Por ejemplo, en lo que tiene que ver con la transgresión de la buena fe o el abuso de confianza, en la indisciplina o desobediencia o en las ofensas verbales o físicas.

La incertidumbre alcanza cotas máximas en lo que se refiere al despido colectivo. Las divergencias en la transposición de la Directiva 98/59, de 20 de julio, relativa a la aproximación de las legislaciones de los Estados miembros que se refieren a los despidos colectivos, han desembocado en diversos pronunciamientos del TJUE sobre el ámbito del despido colectivo, que han obligado al Tribunal Supremo a revisar sus fallos sobre tal cuestión. Todo ello abre un escenario de duda en cuanto

${ }^{10}$ STS de 17 de julio de 2014, (Ro. 32/2014), de 27 de enero de 2014, (Ro. 100/13), de 26 de marzo de 2014 (Ro. 158/2013) y más recientemente STS de 10 de julio (Ro. 1332/2017).

${ }^{11}$ DE LA PUEBLA PINILLA, A.: "El despido por causas empresariales", en AEDTSS: Reestructuraciones empresariales. XXXI Congreso Anual de la Asociación Española de Derecho del Trabajo y de la Seguridad Social, Ministerio de Trabajo y Economía Social, Madrid, 2021, pp. 183 y ss. 
Beatriz Rodríguez Sanz de Galdeano La ineficacia de la regulación legal de despido y su necesaria reconsideración...

al carácter colectivo del despido y a la necesidad de abrir periodo de consultas ${ }^{12}$. La consecuencia de no seguir tal procedimiento, en caso de que el despido sea colectivo, es la nulidad.

\subsection{Escaso recurso a otras vías alternativas al despido en caso de crisis}

Una de las características de nuestro sistema de relaciones laborales es que ante una situación de crisis el empresario opta por el ajuste de personal, en primer término, a través de la extinción de contratos temporales y, en segundo término, por la vía del despido en el caso de contratos indefinidos.

A diferencia de otros países de nuestro entorno, en el caso español no resulta tan habitual el recurso a la suspensión de contratos o la reducción de jornada. En el marco de la anterior crisis se trató de incentivar el recurso a medidas de flexibilidad interna, como la suspensión de contrato o la reducción de jornada. De hecho, la reforma del año 2012 introdujo importantes cambios en el procedimiento que consistían en la eliminación de la necesaria autorización administrativa y en la posibilidad de adopción unilateral por el empresario de la decisión de suspensión o reducción, una vez concluido el periodo de consultas.

Una de las características diferenciales que ha tenido la crisis económica derivada de la pandemia, ha sido el recurso generalizado de las empresas a los instrumentos de regulación temporal del empleo (ERTEs), en lugar de a los despidos y con preferencia, en ocasiones, sobre las extinciones de contratos temporales de empleo. En el origen de esta actuación empresarial se encuentran dos factores, por un lado, el apoyo gubernamental vía bonificaciones sociales a este tipo de actuación empresarial, que se ha visto acompańado de la prohibición de adopción de medidas extintivas; por otro lado, la particularidad de esta crisis, que se esperaba estacionaria y no definitiva.

La experiencia adquirida durante esta situación de crisis y los buenos resultados que, por el momento, ha tenido en lo que tiene que ver con la evitación de la destrucción de empleo, puede llevar a explorar la normalización de este tipo de medidas de flexibilidad interna, como alternativa al despido, en aquellos supuestos en los que se prevea que la crisis de la empresa obedece a razones transitorias.

\subsection{Proliferación de las alegaciones del despido nulo y reclamación de indemnizaciones adicionales}

Un breve análisis de las resoluciones judiciales de los últimos ańos permite advertir la proliferación en las demandas en materia de despido de la pretensión principal de declaración del despido nulo por vulneración de derechos fundamentales ${ }^{13}$.

Hay dos factores fundamentales que pueden explicar esta tendencia. En primer lugar, el hecho de que la vulneración de derechos fundamentales ha quedado como último resquicio al que aparejar la sanción de nulidad del despido. Habría que añadir únicamente los supuestos en los que no se observa el trámite procedimental adecuado en los despidos colectivos.

Junto a ello, el otro motivo que explica esta tendencia es que en los casos de vulneración de derechos fundamentales se ha considerado necesario el reconocimiento de una indemnización

\footnotetext{
${ }^{12}$ En cuanto al ámbito del cómputo vid.: STJUE de 13 de mayo de 2015 (asunto C-392/13, Rabal Cañas); de STS de 17 de octubre de 2016 (Ro. 36/2016); STJUE de 11 de noviembre de 2020 (asunto C-300/19, Marclean Tecnolologies); en cuanto a las extinciones que deben ser computadas vid. STJE de 11 de noviembre de 2015 (asunto C-422-15, Pujante Rivera).

${ }^{13}$ RODRÍGUEZ-PIÑERO ROYO, M, "Algunos aspectos jurídicos de la propuesta de contrato único", Relaciones Laborales, 2010-I, pp. 1241 y ss, ya advertía del riesgo de que el trabajador estuviera tentado en alegar falsamente vulneración de derechos fundamentales con el propósito de obt4ner una indemnización mayor o la nulidad del despido.
} 
adicional. Puede considerarse ya una jurisprudencia consolidada la que entiende que esta indemnización pretende la reparación del daño derivado de la vulneración del derecho fundamental y que puede calcularse teniendo en cuenta la cuantía de las sanciones que el TRLISOS recoge para los supuestos de infracción administrativa ${ }^{14}$. Además, recientemente, el Tribunal Constitucional ha señalado que cabe el reconocimiento de una indemnización adicional en los casos en los que, aunque el despido no sea declarado nulo, se hayan aportado por el empresario pruebas ilícitas, obtenidas con vulneración de derechos fundamentales ${ }^{15}$.

\subsection{Recurso masivo a la contratación temporal fraudulenta como instrumento de flexibilidad}

Los datos sobre la temporalidad en Espańa demuestran cómo en nuestro país existe una tendencia patológica a recurrir a la contratación temporal sin causa. Los datos resultan elocuentes. De total de asalariados en el primer trimestre del año 2021 un $23 \%$ lo eran con contrato temporal, en el mismo trimestre del año 2020 ese porcentaje se elevaba al $25 \%$. Los datos comparativos del año 2019 elaborados por Eurostat señalan que la tasa de temporalidad en España se situaba en un 24,2\%, freten te al 15,3 de Francia, o al 10,1 de Grecia. Los datos de las estadísticas del Ministerio de Trabajo seńalan como en el año 2020 se realizaron 15.943 contratos, de los cuales 14.397 fueron temporales, en el año 2019 del total de contratos (22.512), 20.352 fueron temporales ${ }^{16}$.

Las empresas recurren, por tanto, de forma mayoritaria a la contratación temporal. Las razones de ello se encuentran sin duda en los menores costes de extinción de este tipo de contrato La extinción de los contratos temporales de obra o servicio y eventual lleva aparejada una indemnización de 12 días de salario; en el caso de los contratos formativos y de interinidad no existe indemnización alguna.

Junto a ello, el fraude asociado a este tipo de contratos resulta asumible por el empresario ${ }^{17}$. No suele ser tan habitual en estos casos de extinción de contrato temporal la reclamación judicial de la improcedencia y la consiguiente indemnización de 33 días. Por otro lado, a pesar de que contemplan sanciones administrativas para este tipo de prácticas, lo cierto es que la labor de vigilancia de la Inspección no consigue resultar efectiva.

Por último, las medidas legislativas expresamente introducidas para evitar el fraude en la contratación temporal, consistentes en la consideración como indefinidos de los trabajadores que acumulen 24 meses con dos o más contratos temporales en un periodo de treinta, ha traído consigo un mayor recurso a la rotación de trabajadores como vía para eludir la prescripción normativa.

\section{El marco normativo internacional y su impacto en la regulación espańola de despido y en la interpretación de los tribunales}

El modelo legal de despido es, sin duda, un pilar fundamental del marco normativo laboral y en general del sistema de relaciones laborales. Su configuración determina en buena medida el conjunto de la relación laboral y también es un componente esencial para entender el funcionamiento del mercado de trabajo. Por ello, tradicionalmente se ha tratado de una cuestión que ha sido abordada por los legisladores nacionales y ha dado lugar a diferentes modelos en el conjunto

\footnotetext{
${ }^{14}$ Vid., entre otras: SSTS de 8 de julio de 2014 (rec. 282/2013), de 2 de febrero de 2015 (rec. 279/2013), de 5 de octubre de 2017 (rec. 2497/2015), de 13 de diciembre de 2018 (rec. 3/2018).

${ }^{15}$ STC 61/2021, de 15 de marzo.

${ }^{16}$ Disponible en https://www.mites.gob.es/estadisticas/bel/MLR/index.htm

${ }^{17}$ CONDE-RUIZ, J.I. y LAHERA FORTEZA, J., “Contra la dualidad laboral”, op. cit., p. 105.
} 
de países europeos. Hasta hace poco, los únicos instrumentos normativos internacionales que introducían ciertas reglas comunes en la regulación interna eran el Convenio 158 OIT de 1982, ratificado por España en 1985 y, en el ámbito comunitario, la Directiva 98/59, de 20 de julio, sobre despidos colectivos.

No obstante, la reciente ratificación por España de la versión actualizada de la Carta Social Europea aprobada por el Consejo Europeo el 3 de mayo de 1996 (en adelante CSE) pueden obligar a España a una reconsideración de su régimen legal de despido en aras de adecuarlo a las resoluciones del Comité de Derechos Sociales, sobre el alcance del art. 24 de la Carta relativo al despido.

\subsection{Despido causal y tutela judicial}

Tanto el Convenio de la OIT como el art. 24 de la Carta Social Europea parten de la necesidad de que el despido tenga una justificación causal, bien relacionada con la capacidad del trabajador (según convenio de la OIT) o sus aptitudes o conducta (CSE), bien relacionada con necesidades de funcionamiento de la empresa, establecimiento o servicio.

Con el fin de velar por que efectivamente esto es así, tanto el Convenio como la Carta, contemplan la necesidad de que el trabajador pueda recurrir la decisión empresarial ante un órgano imparcial.

Asimismo, merece la pena destacarse, por las razones que luego se expondrán, que el Convenio 158 exige que en caso de que el empresario base su decisión extintiva en actos relacionados con la conducta del empleado, éste ha de poder defenderse de tales cargos en un trámite previo, a menos que no resulte razonable para el empleador concederlo.

La consecuencia que, tanto el Convenio de la OIT, como la CSE, anudan a la declaración del carácter injustificado de la terminación de la relación laboral es la necesidad de "anular la terminación y eventualmente ordenar o proponer la readmisión del trabajador", no obstante, los organismos encargados de revisar el despido "tendrán la facultad de ordenar el pago de una indemnización adecuada u otra reparación que se considere apropiada", según la dicción literal del art. 10 del Convenio, o " una indemnización adecuada" o " reparación apropiada” según la redacción del apartado b) del art. 24 de la CSE.

Partiendo de este marco regulador, resulta claro que en ningún caso cabe el despido sin causa y que el trabajador debe tener garantizada la tutela frente a las decisiones empresariales extintivas. También resulta claro que las consecuencias de esa tutela judicial pueden consistir, bien en la condena al empresario al pago de una indemnización, bien en el reconocimiento al trabajador del derecho al reingreso.

En una primera aproximación parece que el ordenamiento español parece ajustarse suficientemente a las exigencias de esta normativa internacional. De acuerdo con la regulación interna, el empresario que desee despedir deberá alegar una justa causa. El trabajador puede reclamar dicha decisión, primero ante los órganos de solución extrajudicial y, segundo, en vía judicial. Se contempla asimismo como reparación bien la declaración de nulidad del despido con la condena a la readmisión, para los casos en los que exista vulneración de derechos fundamentales, bien el pago de una indemnización por despido improcedente a razón de 33 días de salario por ańo de servicio.

El problema, sin embargo, viene determinado porque el carácter tasado de la indemnización conlleva, en primer lugar, que el empresario conozca el coste del despido sin causa con antelación, lo cual abre la vía, en ocasiones, a prácticas cercanas al despido libre, consistentes en alegar una causa absolutamente ficticia o simplemente no alegar causa alguna y reconocer la improcedencia del 
despido y asumir el pago de la correspondiente indemnización ${ }^{18}$; en segundo lugar, que la indemnización en los casos en los que el trabajador acumula menos antigüedad, pueda resultar insuficiente.

Esto también se ve en parte propiciado por la eliminación de los salarios de tramitación y por la posibilidad de reconocer por parte del empresario en vía extrajudicial la improcedencia del despido.

Desde un sector doctrinal y ya desde antiguo se ha venido advirtiendo de la posible irregularidad de estas actuaciones empresariales y, muy en particular, de la regulación interna que las permite y, en los últimos ańos, se reclama una revisión de los mecanismos de tutela en caso de despido injustificado. El contrapunto de esta corriente lo marcan otras propuestas, tal y como se ha señalado anteriormente, que apuestan por reducir el número de contratos y revisar la indemnización por despido ${ }^{19}$, e incluso por la inclusión de un contrato único que permitiera el despido por causas empresariales sin posterior control judicial ${ }^{20}$. En el fondo de las primeras propuestas late la necesidad de garantizar una reparación adecuada al trabajador. Con las segundas propuestas se persigue eliminar la precariedad y dualidad de nuestro mercado de trabajo estimulando el recurso a la contratación indefinida.

$\mathrm{Al}$ margen de los objetivos de una y otra propuesta lo cierto es que en el marco de este debate no podemos olvidar las exigencias derivadas de la normativa internacional y, en concreto, cómo el Comité ha interpretado el art. 24 en lo que tiene que ver con la necesidad de una reparación suficiente.

\subsection{Necesidad de una reparación suficiente: la novedosa interpretación del Comité Europeo de Derechos Sociales y su impacto en el ordenamiento español}

El segundo elemento requerido por el Convenio de la OIT y por la CSE, además de la causalidad, es que las legislaciones nacionales contemplen una reparación apropiada. Ahora bien, el entendimiento de qué sea una reparación suficiente ha experimentado un giro radical, que ha de tener repercusiones en nuestro ordenamiento, tras las últimas Resoluciones del Comité Europeo de Derechos Sociales.

En el caso español, tal y como se ha visto, la indemnización por despido se articula en tres niveles: varía desde los 12 días por año trabajado en el caso de extinción de contrato temporal, hasta los 20 en los casos de despido objetivo procedente y hasta los 33 días en caso de despido improcedente.

Podría pensarse, por tanto, que el régimen legal español se adecúa a la normativa internacional. De hecho, durante los ańos de vigencia del Convenio de la OIT, que contempla expresamente también la necesidad de una reparación suficiente, no se había planteado de una forma tan contundente que la legislación interna vulnerase dicho principio.

Sin embargo, el debate en torno a la reparación suficiente ha resurgido, tras la ratificación por Espańa de la CSE y, sobre todo, tras las últimas Resoluciones del Comité en las que se reafirma en su interpretación sobre el concepto de indemnización adecuada. Estas resoluciones inevitablemente nos deben llevar a un análisis y reconsideración del sistema español de indemnización tasada ${ }^{21}$.

\footnotetext{
${ }^{18}$ Recientemente el Tribunal Constitucional Italiano en su sentencia n. 59 de 24 de febrero de 2021, ha señalado que resulta inconstitucional la normativa que permite al juez no aplicar la readmisión del trabajador como sanción en los casos de despido sin causa. Comentada por BAYLOS GRAU, A., "La corte constitucional italiana prosigue su labor de imponer garantías que limitan la reforma del despido del 2012", disponible en https://baylos.blogspot.com/2021/04/la-corte-constitucional-italiana.html

${ }^{19}$ Vid. al respecto CONDE-RUIZ, J.I. y LAHERA FORTEZA, J., "Contra la dualidad laboral”, op. cit., p. 111, quien aun reconociendo que sería políticamente dificultoso propone replantearse a la baja la indemnización del despido objetivo en caso de procedencia y aumentar al alza la indemnización en caso de fraude en la contratación temporal sin causa

${ }^{20}$ BENTOLILLA, S. y JANSEN, M., "La viabilidad jurídica del contrato único", Universidad Autónoma de Madrid, 2010.

${ }^{21}$ MURCIA CLAVERÍA, A., "Despido improcedente: una sanción mínima y polémica que no garantiza el derecho a la pro-
} 
Ya en el año 2016, el Comité encargado de interpretar la CSE en su resolución de 8 de septiembre (Finnish Society of Social Rights v. Finlande), había señalado que el término reparación adecuada ante un despido injustificado debía comprender, bien el reembolso de las pérdidas financiera sufridas entre la fecha del despido y la decisión del organismo encargado de enjuiciarlo, bien la posibilidad de reincorporación una indemnización lo suficientemente elevada como para disuadir al empresario y reparar los dańos sufridos por el trabajador. Señalaba, además, que el establecimiento de un límite máximo en la indemnización que impida que la reparación sea proporcional a la pérdida sufrida y suficientemente disuasoria es contrario a la Carta.

En su reciente resolución de 11 de septiembre de 2019, el Comité ha tenido ocasión de reafirmarse en esta interpretación. Mediante este pronunciamiento el Comité daba respuesta a la reclamación de la CGIL frente al Decreto 23/2015, de 4 de marzo que había introducido la indemnización tasada en el ordenamiento italiano, que hasta entonces había sido un referente en la protección frente al despido ${ }^{22}$. El Comité concluye que un sistema tasado, que tenga como efecto que las indemnizaciones no son proporcionales al perjuicio, ni suficientemente disuasorios es contrario a la Carta. Señala, además, que en caso de que se prevean indemnizaciones tasadas, la víctima tiene que tener la posibilidad de reclamar una indemnización complementaria ${ }^{23}$. A esta misma conclusión apuntaba la sentencia 194/2018, de la Corte constitucional italiana de 26 de septiembre de $2018^{24}$.

La cuestión también se ha planteado en Francia, como consecuencia de la última reforma introducida por la orden núm. 2017-1387, de 22 de septiembre de 2017, que contempla también un sistema de indemnizaciones tasadas. Si bien, respecto del régimen francés no se ha pronunciado el Comité de Derechos Sociales porque ha inadmitido los recursos presentados por organizaciones sindicales debido a problemas formales de legitimación. No obstante, los tribunales franceses, obligados a aplicar las disposiciones de la Carta, de forma directa, están concluyendo también que el régimen francés conculca el art. 24 de la Carta.

Teniendo en cuenta este marco normativo y la interpretación de la Carta, cabe aventurar que un régimen, como el español, que contempla indemnizaciones tasadas para el despido sin justa causa y que, conforme con la interpretación jurisprudencial, impide la obtención de una reparación adicional por otra vía, puede resultar contrario al art. 24 de la Carta ${ }^{25}$. Así comienzan a plantearlo, como posteriormente se verá, algunas sentencias de juzgados inferiores.

tección contra un despido injustificado" en MURCIA CLAVERÍA, A. y VALDÉS DAL-RÉ, F. (dirs.) El despido en España tras la reforma laboral, Madrid Francis Lefebvre 2018, pp. 119-145; MOLINA NAVARRETE, C., "La indemnización disuasoria por despido arbitrario, entre ortos (auroras) y ocasos (crepúsculos): :justicia resarcitoria o 'justicia del cadí'?", Estudios Financieros. Revista de Trabajo y Seguridad Social, núm. 451, 2020, pp. 185-208. Se hace también eco de los principales hitos jurisprudenciales en torno a esta cuestión ROJO TORRECILLA, E., "El trabajo no es una mera mercancía. Las aportaciones del Tribunal Constitucional italiano en su sentencia de 26 de septiembre de 2018 /y de algunos Conseil de Prud'hommes franceses) sobre el debate jurídico de la indemnización tasada por despido", El blog de Eduardo Rojo, 9 de enero de 2019, disponible en http://www.eduardorojotorrecilla. es/2019/01/el-trabajo-no-es-una-mera-mercancia-las.html.

${ }^{22}$ SPEZIALE, V., "La nueva regulación en Italia del contrato indefinido de "tutela creciente" entre el derecho economicismo y los imperativos constitucionales” Temas Laborales, núm. 131, 2015, pp. 13 y ss.

23 "Le Comité rappelle que tout plafnnement qui aurait pour effect que les indemnitès octroyées ne sont pas en rapport avec le prejudicce subi et ne sont pas suffisamment dissuasives este en principe, contrarie à la Charte, comme là relevé aussi, dansune certaine mesure, la Cour constitutionnelle dans sa decisión nº194/2018. En cas de plafonnement des indemnités accordées en compensation du préjudice matériel, la vitime doit pouvoir demander réparation pour le préjudice moral subipar dàutres voies de droite ete les juridictions competentes pour accorder une indemnisation pour le préjudice matériel et moral subi doivent se prononcer dans un délai raisonnable (...):

${ }^{24}$ Comentada por BAYLOS GRAU, A.: "El contrato único italiano declarado inconstitucional”, disponible en https://baylos. blogspot.com/2018/10/el-contrato-unico-italiano-declarado.html

${ }^{25}$ BAYLOS GRAU, A., "Despido injustificado e indemnización: marco regulador deficiente y reforma necesaria", Revista de Derecho Social, núm. 93, 2021, pp. 7 y ss; MOLINA NAVARRETE, C., "El despido con causa irreal: ;cambios augurables con la ratificación de la Carta Social Europea revisada?. Comentario a la Sentencia del Tribunal Superior de Justicia de Andalucía/Sevilla 3571/2020, de 19 de noviembre”, Estudios financieros. Revista de trabajo y seguridad social, núm. 455, 2021, pp. 230 y ss. 
Beatriz Rodríguez Sanz de Galdeano La ineficacia de la regulación legal de despido y su necesaria reconsideración...

\subsection{Trámite previo al trabajador en el supuesto de despido disciplinario}

En lo que se refiere al despido disciplinario, una cuestión que parece haber pasado inadvertida cuando se analiza la regulación española, es que el art. 7 del Convenio 158 OIT exige que se dé al trabajador la posibilidad de defenderse de los cargos formulados contra él antes de darse por terminada la relación de trabajo, salvo "que no pueda pedirse razonablemente al empleador que le conceda esta posibilidad".

Parece que el Convenio de la OIT está pensando en que se abra un trámite de audiencia previa al trabajador. La regulación española, sin embargo, no contempla este trámite, salvo para el caso de los representantes de los trabajadores. Pudiera pensarse que este requisito se encuentra suficientemente cumplido en la medida en que el trabajador puede defenderse de los cargos a través de la reclamación, ya en vía extrajudicial. Sin embargo, el Convenio exige que el trámite se abra antes de la extinción del contrato.

$\mathrm{Al}$ margen del posible incumplimiento de la regulación internacional, como se verá a continuación, la apertura de este trámite previo puede resultar útil para identificar aquellos supuestos de despido arbitrario, que pueda justificar la previsión de indemnizaciones adicionales, a la legalmente tasada, suficientes y disuasorias, en línea con lo requerido por la carta.

\section{Algunas propuestas de reforma}

Llegados a este punto, cabe advertir que la regulación del despido resulta ineficaz, por cuanto el empresario, recurre bien a la extinción temporal, bien al reconocimiento de la improcedencia del despido para ajustar de forma rápida la plantilla. Resulta, asimismo, indiscutido que el mercado de trabajo español adolece de una dualidad entre trabajadores temporales e indefinidos. La realidad también demuestra que las empresas utilizan fraudulentamente la contratación temporal para conseguir la flexibilidad deseada.

Junto a ello, resulta concluyente la interpretación del Comité sobre la falta de adecuación a la Carta de los sistemas de indemnización tasadas, como el español.

Partiendo de estas premisas, en un afán puramente propositivo y con un objetivo constructivo, ante la posibilidad apuntada de próximas reformas en el régimen de contratación, se plantean a continuación algunas premisas que debieran presidir cualquier actuación al respecto y algunas propuestas de actuación.

\subsection{Propuestas legales para la certidumbre en torno a las causas de extinción del contrato y evitación del despido sin causa. La apertura de un trámite previo al trabajador}

Tal y como se ha puesto de manifiesto uno de los motivos de la ineficacia de la regulación del despido es la huida del empresario de los cauces legales causales para proceder a su realización. Resulta habitual que el empresario prefiera evitar los costes e incertidumbre del proceso y prefiera reconocer la improcedencia. Junto a ello, el diseño legal admite prácticas de despido libre, sin causa, con la única consecuencia de condenar al empresario a una indemnización tasada.

Hasta ahora las actuaciones legales se han centrado en tratar de otorgar mayor seguridad jurídica en cuanto a la causa en los despidos por crisis. Las sucesivas reformas han tratado de definir mejor las conocidas como causas ETOP, en un afán por dar seguridad jurídica, si bien, no han evitado la necesidad de que el empresario deba justificar la razonabilidad y proporcionalidad de la 
medida extintiva. Los intentos legislativos se han centrado en la redefinición de la causa, con el fin confesado de que la simple acreditación de la causa permitiera el despido. No obstante, los Tribunales, tal y como se ha visto, han seguido exigiendo la razonabilidad y la conexión funcional, aunque en algunos casos como el de las causas organizativas o técnicas, de forma mucho más atenuada ${ }^{26}$.

Quizás, por ello, sea necesario optar por un planteamiento más innovador, que, en línea con lo que hacen otros países de nuestro entorno, se centre en abrir vías que permitan constatar la buena fe empresarial en la adopción de la decisión extintiva por causas ETOP. Con ello se evitaría también la proliferación de las prácticas de despido libre. Se trataría de introducir elementos que otorguen ciertas garantías sobre la razonabilidad de la causa.

En este punto puede ser útil dirigir la mirada a otros ordenamientos y reconsiderar asimismo el objetivo de las reformas, de manera que no se incida tanto en la causa como en la buena fe empresarial y en la razonabilidad de la medida. El objetivo es garantizar una indemnización para el caso de despido objetivo con causa y contemplar indemnizaciones adicionales, más allá de las tasadas legalmente para el despido improcedente, en aquellos supuestos en los que se demuestre la mala fe empresarial en la alegación de la causa económica.

Para ello, cabría plantearse la oportunidad de que el empresario, también en estos despidos individuales, abriera un periodo de consultas con el trabajador y sus representantes en el que se negociara de buena fe en aras a acreditar tanto la causa como la necesidad de amortización del puesto y la imposibilidad de recolocar y reubicar al trabajador en la empresa. Esto es lo que ocurre en ordenamientos como el británico, que contempla la posibilidad de aumentar la indemnización en función del comportamiento de las partes en el procedimiento. Lo mismo sucede en Francia, que obliga a la convocatoria del trabajador y a la acreditación de la imposibilidad de recolocación ${ }^{27}$.

En el caso del despido por causas objetivas referidas al trabajador, la definición de las causas que justifican la extinción del contrato de trabajo no ha experimentado grandes cambios en nuestro ordenamiento. El art. 52 señala que estas causas serán: ineptitud sobrevenida, falta de adaptación del trabajador, causas ETOP y extinción de contratos en el marco de la ejecución de programas y planes públicos sin dotación económica estable. El cambio de mayor relevancia ha sido la eliminación del absentismo como causa justificativa del despido objetivo.

Por otro lado, la jurisprudencia ha ido concretando el modo en que debe entenderse la concurrencia de dichas causas. Por lo tanto, en la práctica, existe una mayor certidumbre en torno a la concurrencia de estas causas.

No obstante, en línea con lo ya apuntado, sería conveniente explorar un reforzamiento de las obligaciones previas del empresario de búsqueda de soluciones alternativas al despido, en casos tales como ineptitud sobrevenida o falta de adaptación a innovaciones técnicas.

En el ámbito del despido disciplinario también ha existido una cierta estabilidad en la formulación legal de las causas y la jurisprudencia ha efectuado una labor considerable en la unificación de los criterios interpretativos, si bien, existen todavía en la práctica zonas grises en la apreciación de algunas de estas causas.

Nuevamente, con el objetivo de desincentivar las actuaciones empresariales extintivas basadas en una causa disciplinaria absolutamente inexistente sería necesario plantearse una reformulación de los requisitos de despido disciplinario con el fin de vedar dichas actuaciones. Este replanteamiento podría centrarse no tanto en la definición de las causas sino en la apertura de un expediente previo

${ }^{26}$ MOLINA NAVARRETE, C., "El despido por causas empresariales", op. cit., pág. 237, reconoce la mejora de la seguridad jurídica en torno a la causa como la gran deuda.

${ }^{27}$ ÁLVAREZ DEL CUVILLO, A., "Informe sobre la regulación del despido en Europa”, Temas Laborales, núm. 99, 2009, pp. 259 y ss. No obstante, tal y como se ha apuntado, en este país se ha introducido una reforma para limitar la indemnización tasada por despido. 
en el que el empresario debiera concurrir de buena fe para probar la realidad de las causas alegadas y el trabajador pudiera realizar las oportunas alegaciones. El despido sería considerado improcedente en caso de que no concurriera causa y podría conllevar una reparación adicional en los casos en los que la conducta empresarial en ese trámite previo permitiera concluir que existe una falta absoluta de causa y que el despido responde a motivos arbitrarios.

Esta reforma iría en línea con la regulación del Convenio de la OIT, que exige un trámite previo al trabajador. Por lo demás, este trámite existe con matices en países como Reino Unido, Francia o Italia ${ }^{28}$.

\subsection{El replanteamiento del sistema de reparación: la necesaria indemnización adicional en los casos de despido sin causa}

Tal y como se acaba de señalar la consecución de una mayor certidumbre en cuanto a la causa debería ir acompañada de la previsión de una reparación adicional, suficiente y disuasoria, para los casos en los que el empresario ha actuado con absoluta discrecionalidad.

La cuestión es cuál ha de ser el mecanismo de reparación adecuada y disuasoria. En algunos recientes pronunciamientos judiciales se ha vuelto a proponer la opción de la nulidad como la sanción al despido sin causa ${ }^{29}$. Se trata de pronunciamientos que han tenido como telón de fondo la ambigua legislación de emergencia promulgada en el marco de la pandemia que prohíbe el despido en aquellas empresas que se hubieran acogido a las medidas extraordinarias de apoyo a los ERTEs. La cuestión que se plantea es cuál ha de ser la calificación del despido en estos casos, si la improcedencia o la nulidad. El pronunciamiento del Juzgado de lo social de Barcelona de 31 de julio de 2020 defiende la vía de la nulidad y esgrime como argumento principal que la indemnización legal por despido no resulta disuasoria y que, en consecuencia, podría vulnerar lo dispuesto en el Convenio 158 OIT y también en el art. 24 de la Carta. Señala literalmente la sentencia “..., si la indemnización que legalmente corresponde para un despido sin causa (en nuestro ordenamiento calificado como improcedente) es tan exigua que no supone esfuerzo financiero alguno para la empresa, los efectos prácticos son los propios de un desistimiento, sin otra causa que la simple voluntad del a empleadora. Y ello podría ser contrario a las disposiciones del Convenio no 158 de la OIT". En consecuencia, en el citado caso, consideró el juzgador que procedía la aplicación del art. 10 del convenio que permite al juzgado ordenar el pago de una indemnización adecuada cuando no se pudiera anular la terminación del contrato y ordenar la readmisión.

La sentencia fue, sin embargo, revocada por la sala de lo social de TSJ (Cataluña) de 23 de abril de 2021 (rec. 5233/2020), que tras una profusa revisión de la evolución de la regulación en materia de despido, concluye que en nuestro ordenamiento no está admitido el despido sin causa, y que, en caso de producirse, la consecuencia es el pago de una indemnización que, en el caso espańol, considera la sentencia resulta conforme con la exigencia del Convenio de la OIT de garantizar una reparación apropiada. Señala literalmente la sentencia "La conclusión que debe sacarse de este análisis de las normas y jurisprudencia internacionales, es que de ellas no se deduce en modo alguno que la legislación española que declara improcedente el despido realizado sin alegación de causa, con la indemnización correspondiente, contradiga tales normas internacionales, en la medida en que esta indemnización está prevista expresamente por ellas como consecuencia del incumplimiento del

\footnotetext{
${ }^{28}$ Ministerio de Empleo y Seguridad Social: "Francia. Descifrando la reforma del Código de Trabajo", Actualidad Internacional Sociolaboral, núm. 223, pásg 134 y ss.

${ }^{29}$ SJS (Barcelona) de 31 de julio de 2020 (Procedimiento 348/2020) y SJS (Madrid) de 21 de febrero de 2020 (Procedimiento $843 / 2019)$
} 
principio de causalidad del despido ...”. Ahora bien, sentada esta premisa general, la sentencia reconoce que en el caso de autos la indemnización, debido a la escasa antigüedad del trabajador, resultaba exigua. Y considera que, en este caso concreto, de forma excepcional y en aplicación del art. 10 del Convenio OIT 158 hubiera resultado posible fijar una indemnización adicional a la legalmente tasada, con el fin de garantizar una reparación adecuada. No obstante, para fijar dicha indemnización adicional se requiere por parte del trabajador la prueba precisa d ellos dańos adicionales.

Con base también en el Convenio de la OIT 158, aunque en un supuesto de despido sin causa anterior a la pandemia, el JS de Madrid en sentencia de 21 de febrero concluyó que un despido sin causa debía sancionarse con la nulidad. La sentencia fue revocada por la sala en sentencia de 3 de noviembre de 2020 (rec. 587/2020), que considera que la indemnización tasada es acorde con la exigencia de una indemnización adecuada en supuestos de extinción injustificada del Convenio 158 OIT.

Resulta, evidente, por tanto, la actualidad del debate y la divergencia en nuestra doctrina judicial, con argumentos sólidos en uno y otro sentido. Ahora bien, la reciente ratificación por España de la Carta Social Europea en su versión revisada debe llevar a un replanteamiento de los términos del debate que tenga en cuenta la interpretación del Comité ${ }^{30}$. En efecto, si solo se tuviera en cuenta el convenio 158 de la OIT podría dudarse de si la indemnización tasada resulta una reparación adecuada, salvo, a lo sumo, en casos manifiestamente excepcionales como el abordado por la sentencia del juzgado de Barcelona. Sin embargo, la ratificación de la Carta aconseja una revisión del régimen legal interno, que tenga en cuenta la interpretación realizada por el Comité de su art. 24, que, tal y como se ha visto, concluye que los sistemas de indemnización tasada pueden no ser suficientes cuando no resultan disuasorios ${ }^{31}$.

Teniendo en cuenta esta interpretación, parece que ha de revisarse la regulación del despido con el fin de contemplar esa indemnización suficientemente disuasoria. La opción más radical consistiría en extender la sanción de nulidad del despido a cualquier tipo de despido improcedente, realizado sin observación de los requisitos legales de fondo y forma ${ }^{32}$. Sin embargo, también podría mantenerse una opción intermedia que contemplara la indemnización tasada para los casos de despido improcedente pero que abriera la posibilidad de una indemnización superior o adicional, según el criterio del juez de instancia, para aquellos casos de despido con falta absoluta de causa.

De tal manera que, podrían contemplarse tres tipos de sanciones para el despido realizado sin observar los requisitos legales. La tradicional nulidad, que conlleva la readmisión y el pago de los salarios de tramitación. La improcedencia, con una indemnización de 33 días para los casos en los que el empresario no acredite la causa o incurra en defectos formales. La improcedencia con una indemnización adicional en aquellos casos en los que el empresario no observe una conducta razonable en el trámite previo para la acreditación de la causa, bien sea económica o por otras causas objetivas, o bien sea disciplinaria. Se trataría, por tanto, de contemplar una indemnización adecuada y disuasoria del despido arbitrario.

Cabe argüir que esta propuesta puede, aun y todo, no respetar la interpretación del Comité por cuanto en los casos de simple improcedencia, no se abre la vía para una reparación adicional de los posibles dańos. De tal manera que en los casos en los que el trabajador tenga escasa antigüedad

\footnotetext{
${ }^{30}$ (BOE de 11 de junio de 2021), entrada en vigor el día 1 de julio de 2021.

${ }^{31}$ Advierte de los riesgos de un control de convencionalidad difuso y de la conveniencia del recurso al Tribunal Constitucional con el fin de depurar la legalidad interna de forma acorde con la normativa internacional: GOERLICH PESET, J.M., "Redescubriendo el control de convencionalidad: ‘activismo o autocontención judicial?”, LABOS Revista de derecho del Trabajo y Protección Social, vol. 2, núm. 1 (2021), disponible en https://e-revistas.uc3m.es/index.php/LABOS/article/view/6044/4396. MOLINA NAVARRETE, C., "EL despido por causas empresariales", op. cit., p. 246, urge a una intervención legislativa o del TS aclaratoria.

32 BAYLOS GRAU, A., "Despido injustificado e indemnización: marco regulador deficiente y reforma necesaria", Revista de Derecho Social, núm. 93, 2021, págs. 7 y ss.
} 
la indemnización puede que no sea suficiente. Ciertamente, existe incertidumbre en cuanto a si este sistema respeta lo dispuesto en la Carta. Si bien se trata de daños difícilmente cuantificables

Por último, en aquellos casos en los que la situación de crisis se prevea definitiva, podría ser necesario plantearse medidas de apoyo a las empresas en la asunción de la indemnización por despido procedente. Se trataría, de algún modo, de socializar este riesgo, evitando que la empresa, en una situación de dificultad económica, tuviera que hacerse cargo de la totalidad de las indemnizaciones. En este sentido, podría ser necesario recuperar el papel del FOGASA como organismo de aseguramiento de estas indemnizaciones y reducir la indemnización a cargo del empresario.

\subsection{Acompañar a las empresas en crisis para evitar el despido}

Con motivo de la crisis del año 2010, el legislador español trató de introducir reformas que estimularan el recurso a las suspensiones de contratos y reducción de jornada como vía alternativa al despido. Esta línea de actuación ha presidido la actuación legislativa de emergencia durante la crisis económica provocada por la pandemia originada por el Coronavirus. El recurso a los ERTE promocionado por medio de intervenciones púbicas ad hoc que exoneraban a las empresas de las cotizaciones sociales al tiempo que les imponían obligaciones de mantenimiento del empleo, se ha demostrado como un mecanismo eficaz para paliar los efectos económicos de la crisis sanitaria ${ }^{33}$.

Resulta, por ello, necesario incorporar al ordenamiento español, previsiones que obliguen al empresario a buscar alternativas al despido en situaciones de crisis, sobre todo, cuando la situación de crisis se espera que sea coyuntural. En esta línea, parecen situarse los planteamientos del Gobierno que recoge como objetivo del componente 23 del Plan de recuperación presentado a Europa, la consecución de un mercado más resiliente y señala expresamente que "El Plan prevé también el establecimiento de un mecanismo permanente de flexibilidad interna de las empresas alternativo al despido, reforzando la inversión en formación y recualificación y la prioridad de la reducción de jornada y de suspensión de contrato". ${ }^{34}$

Asimismo, sería interesante apostar por medidas, como las contempladas en otros ordenamientos, tendentes a facilitar la reubicación o readmisión del trabajador despedido cuando desaparece la situación de crisis.

\subsection{Revisión del marco legal de contratación temporal: reducción del número de contratos y aumento de la reparación en caso de fraude}

La revisión de la regulación del régimen de extinción debe abarcar también la reforma legal de la contratación temporal. Desde todos los ámbitos (político, académico, económico) se llama la atención sobre la elevada tasa de temporalidad de nuestro mercado de trabajo y sobre la necesidad de simplificar el número de contratos temporales. Las últimas propuestas del Gobierno, recogidas en el plan para la transición, apuntan a una reducción de los contratos a tres, estable, temporal y formativos. No se especifica nada más al respecto.

\footnotetext{
${ }^{33}$ NAVARRO NIETO, F., "Medidas sociales de acompañamiento y mantenimiento del empleo", en AEDTSS: Reestructuraciones empresariales. XXXI Congreso Anual de la Asociación Española de Derecho del Trabajo y de la Seguridad Social, Ministerio de Trabajo y Economía Social, Madrid, 2021, págs. 279 y ss.

${ }^{34}$ Gobierno de España: Plan de recuperación, transformación y resiliencia, pág 80, disponible en https://www.lamoncloa.gob.es/ temas/fondos-recuperacion/Documents/30042021-Plan_Recuperacion_\%20Transformacion_\%20Resiliencia.pdf
} 
En la actualidad, como es sabido, nuestro ordenamiento laboral contempla cinco tipos de contratos temporales: el de obra o servicio, el eventual, el de interinidad y los contratos formativos para la formación y prácticas. La justificación causal de cada uno de estos contratos está bien definida en la legislación y también la jurisprudencia ha realizado una encomiable labor de aclaración. Sin embargo, lo cierto es que las empresas recurren de forma masiva al contrato de obra y al eventual, como vía de entrada en la empresa debido a sus menores costes de extinción.

Por otro lado, en la práctica, las medidas para evitar el fraude no han tenido el efecto deseado y han generado un efecto de rotación de la mano de obra en puestos temporales. Asimismo, el coste del fraude de ley resulta asumible por las empresas, por cuanto los trabajadores no siempre impugnan la finalización del contrato temporal en fraude de ley y porque el coste de la indemnización resulta asumible debido a la escasa antigüedad que acumulan este tipo de trabajadores.

Teniendo en cuenta este panorama normativo, las últimas propuestas del Gobierno, recogidas en el plan para la transición, apuntan a una reducción de los contratos a tres, estable, temporal y formativos. No se especifica nada más al respecto. También desde el ámbito académico se llama la atención sobre la necesidad de reducir el número de contratos ${ }^{35}$. Con todo, en todas las propuestas se reconoce la necesidad de arbitrar vías que permitan a las empresas, con necesidades temporales reales, el recurso a la contratación temporal. En concreto, se señala que es necesario permitir a las empresas recurrir a la contratación temporal cuando sea necesario sustituir a trabajadores, cuando existan causas organizativas o productivas y también con el fin de formar a trabajadores.

Resulta, por tanto, que en la práctica volvernos a tener las modalidades típicas de contrato temporal (interinidad, obra o servicio, eventual y formativos).

Quizás en este punto la reforma legislativa debiera pasar por clarificar la definición de las causas que justifican el recurso a los contratos de interinidad, eventual y obra o servicio, teniendo en cuenta la cada vez más depurada jurisprudencia al respecto ${ }^{36}$.

$\mathrm{Al}$ margen de lo anterior, también resultaría conveniente replantearse las medidas antifraude. El límite al encadenamiento de contratos no evita el recurso masivo a la contratación temporal, por cuanto, se produce el fenómeno de rotación. Sería necesario, por ello, vincular la limitación no a la persona del trabajador, sino al puesto de trabajo. Por otro lado, resulta recomendable un replanteamiento de la indemnización en caso de fraude en la contratación temporal, en línea con los pronunciamientos del Comité de Derechos Sociales. No bastaría, por tanto, con contemplar una indemnización de 33 días, sino que en estos casos sería necesario abrir la posibilidad de una indemnización adicional, fijada discrecionalmente por el juez, atendiendo a las circunstancias del caso ${ }^{37}$.

\footnotetext{
${ }^{35}$ Resultan muy sugerentes algunas de las propuestas en este ámbito de la contratación temporal de CONDE-RUIZ, J.I. y LAHERA FORTEZA, J., "Contra la dualidad laboral”, op. cit., pp 110.

${ }^{36}$ Sería el momento para incorporar la última jurisprudencia sobre el contrato de obra y la imposibilidad de vincularlo a la duración de la contrata, así como otros pronunciamientos sobre las posibilidades y límites del contrato eventual y de interinidad. Vid. al respecto GOERLICH PESET, J.M., MARTÍN-POZUELO, A.; MOLL NOGUERA, R., “Contratación laboral”, Revista Española de derecho del Trabajo, núm. 2412021.

${ }^{37}$ CONDE-RUIZ, J.I. y LAHERA FORTEZA, J., “Contra la dualidad laboral”, op. cit., pp. 105 y 106.
} 